\title{
PROCESSO DE ENSINO-APRENDIZAGEM NA SOCIEDADE DA INFORMAÇÃO
}

\author{
José Marcos de Oliveira CruZ
}

\begin{abstract}
RESUMO: A sociedade da informação tem colocado novos desafios ao processo de ensino-aprendizagem. A forma de se proceder em relação à construção do conhecimento mudou. $\mathrm{O}$ contato com as fontes de informaçóes tornou-se mais dinâmico, obedecendo a uma lógica nunca vista anteriormente. $\mathrm{O}$ próprio saber tornou-se maleável e instável, necessitando de atualização constante. É com base no contexto dessa sociedade que se pretende refletir sobre processo de ensino-aprendizagem, introduzindo na discussão a perspectiva da bricolagem e da rizomática, que considera a construção do conhecimento diversificada, descentralizada e horizontalizada. Assim, analisar-se-á a relação entre informação e conhecimento, bem como as novas formas de se conceber e produzir o saber. Tal reflexão tem como finalidade pensar sobre os novos paradigmas produzidos pela sociedade da informação, bem como sua repercussão no processo de ensino-aprendizagem.
\end{abstract}

Palavras-chave: Sociedade da informação. Processo de ensino-aprendizagem. Aprendizagem acadêmica.

\section{THE TEACHING-LEARNING PROCESS IN THE INFORMATION SOCIETY}

ABSTRACT: The information society has brought new challenges to the teaching-learning process. The way to tackle knowledge building has changed. The contact with information sources has become more dynamic and obeys to an unprecedented logic. Knowledge itself has become more instable and malleable, requiring constant updates. Faced with such a context, this paper re-thinks the teachinglearning process by introducing into the discussion the perspective

Mestre em Educação e professor da Universidade Federal do Sergipe (UFSE). E-mail: jo_marcruz@yahoo.com.br

Educ. Soc., Campinas, vol. 29, n. 105, p. 1023-1042, set./dez. 2008 
of bricolage and rhizomatics, which considers knowledge construction as diversified, decentralized and horizontalized. It thus analyses both the relation between information and knowledge and the production of new ways of conceiving and producing knowledge. This reflection aims to think about the new paradigms produced by the information society and their repercussions on the teaching-learning process.

Key words: Information society. Teaching-learning process. Academic learning.

Sociedade da informação: entre o excesso de informação e a produção de conhecimento

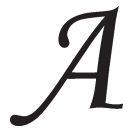

leitura que desejamos realizar para analisar a educação e o processo de ensino-aprendizagem na sociedade da informação terá como fundamento os princípios da bricolagem de Lévi-Strauss (1976) e da rizomática de Deleuze e Guattari (2004). A partir deste "roubo" conceitual, pretendemos refletir as novas estratégias engendradas e utilizadas pelos alunos acadêmicos perante o uso que fazem da internet.

A sociedade da informação é uma realidade decorrente dos novos mercados, meios de comunicação e consumidores desta era que conseguiu transformar o mundo em uma grande sociedade globalizada e globalizante, na qual os bens primordiais são informação e conhecimento. Conforme demonstrou Borges (2000), a sociedade da informação ${ }^{1}$ pode ser caracterizada pelo seu estilo sistêmico, tendo como destaque ser: 1) complexa, graças a seu número de interações, articulação e interdependência entre os elementos de um sistema presente em uma situação; 2) hierárquica, já que parte de estruturas mais simples para estruturas mais complexas; e 3) configurada, em virtude de suas dimensões macro e microscópicas.

A relação entre qualidade e quantidade de informação é, sem dúvida, um dos "calcanhares-de-aquiles" desta sociedade. Por isso o grande desafio está em transformar o imenso volume e o intenso fluxo de informações em conhecimento. A informação é um fator intrínseco a qualquer atividade, ela deve ser conhecida, processada, compreendida e utilizada pela consolidação de serviços, produtos e sistemas de informações. 
A respeito do excesso de informação disponível na internet, $\mathrm{Vi-}$ era (1998), Dowbor (2000) e Demo (2000b) alertam-nos para o fato de as pessoas estarem absorvendo informaçôes que, muitas vezes, têm credibilidade duvidosa. É importante destacar também a necessidade de se saber processar informação, mesmo porque ela, por si, não implica conhecimento, importa mais a capacidade reflexiva e crítica que o indivíduo é capaz de desenvolver ante o conteúdo que ela traz. Informação, sem uma mente que a analise, que a reflita, que a compreenda e que a use adequadamente, é inútil para o crescimento intelectivo do sujeito. A capacidade reflexiva do aluno é elemento essencial para o discernimento do conhecimento, já que é ela que o torna capaz de interpretar, comparar, ponderar e integrar as informações.

Para Jorge (1998) e Falzetta (2000), o excesso de informação ameaça soterrar cada indivíduo, pois, se não há tempo nem disposição para saborear idéias ou refletir sobre suas implicações, fica-se apenas na superficialidade. A avalanche informacional dificulta, por exemplo, a aprendizagem do aluno, pois o acesso a muitos conteúdos associado à falta de tempo para processá-los ou para digeri-los pode deixar o discente na superficialidade do saber.

Observação semelhante é feita por Monteiro (2000), mostrando que a internet é como uma grande vitrine de informações, mas não de conhecimento. A rede é apenas um transporte físico de documentos, ou uma ferramenta que trouxe mudanças cognitivas para o meio de comunicação, mediante suas formas textuais. Nela se tem contato com uma imensidão de elementos informativos, de tal forma que mal se assimila um conteúdo já se passa para outro. Ter acesso ao oceano de informação é algo fascinante. Com apenas alguns cliques podemos acessar informação de qualquer parte do mundo, sem precisar sair do lugar. Com isso, uma das principais dificuldades que a sociedade da informação nos coloca é a de saber selecionar entre milhôes de informações disponíveis.

Carvalho e Kaniski (2000) evidenciaram que a informação passou a ser considerada recurso estratégico de agregação de valor e elemento de competição política e econômica entre os países, estando atrelada à utilização da telemática. Ela pode ser um instrumento modificador ou alienador da consciência do homem, já que sua assimilação produz conhecimento que modifica o estoque mental de saber 
do indivíduo, trazendo comportamentos que têm repercussão em seu desenvolvimento e no da sociedade em que vive.

A crítica feita por esses autores à sociedade da informação é a de que esta informa bem menos do que se imagina. A forma de procedimento ante a informação digital cria uma cultura descartável, pois, como se observa, as informações disponíveis nos bancos de dados, por exemplo, não existem para ser lidas. São informações essencialmente perecíveis e transitórias, que não contêm sínteses ou idéias e que provavelmente não serão relidas ou reinterpretadas no futuro. Neste sentido, a advertência de Gasque e Tescarolo (2004) é para o fato de esta sociedade criar novas formas de aprendizagem e de gestão de conhecimento. Para isso certas capacidades e atitudes gerais precisarão ser mobilizadas, de modo que novas formas de acesso e de manejo da informação sejam desenvolvidas.

Adentrar o oceano de informação pode ser um mergulho no vazio, pois o excesso de movimento gera uma espécie de paralisia. Nessa realidade, a cognição não realiza mergulho no plano da criação de sentidos, já que fica presa a uma exploração contínua e ininterrupta de todas as informações que podem ser acessadas e isso obsta à própria força de problematização e estranhamento que os textos poderiam provocar. O problema é que o fascínio pelo excesso de informações satura o intervalo necessário à virtualização e à criação de outras atualizações.

Conforme nos mostrou Lévy (1999), devemos nos defender do novo dilúvio que enfrentamos com o excesso de informação disponível no ciberespaço. Esta proteção, segundo Kastrup, consiste na utilização da rede como dispositivo politemporal, pois a sua novidade é aproximar tempos muito distintos,

(...) pela internet, temos acesso em tempo zero a bancos de dados, mas também a textos de diferentes tempos, entre os quais alguns existem para serem consultados e outros para serem lidos, interpretados e criticados. A construção de territórios locais e heterogêneos se dá a partir do momento em que mergulharmos no movimento politemporal da rede. (Kastrup, 2000, p. 53)

O mergulho nos textos encontrados, nos extratos disponíveis na rede, exige um intervalo temporal, uma velocidade cognitiva diferente, talvez mais lenta do ponto de vista do movimento sensório-motor. 


\section{Relação professores e alunos na sociedade da informação}

A forma tradicional de conhecimento presente nas escolas centrava-se na figura do professor, sendo este tratado como o "dono do saber". Hoje, percebemos mudanças nesse cenário. $\mathrm{Na}$ era da informação, o espaço de saber do docente foi dando lugar ao de mediador e problematizador do aprender: ele passou a ser visto como aquele que desafia os alunos, mostrando-lhes, entre as várias possibilidades de aprendizagem, caminhos que poderão ser percorridos.

Maraschin (2000) evidencia que o papel da escola e do professor não é divulgar informações, mas sim instigar o conhecimento. A escola da informação e da memorização deve dar lugar à escola do conhecimento e da descoberta. A descoberta e a construção de modos criativos de conhecimento, usando as múltiplas e variadas modalidades de informação já disponíveis, devem ser o foco da educação escolar.

Viera (1998), citando Vigotski, mostra que o aluno e o professor terão à sua disposição recursos tecnológicos atuais e de grande interesse. Esses recursos podem funcionar como mediadores culturais, isto é, instrumentos que permeiam significantemente nossa relação com o mundo. Um dos principais mediadores do processo de ensino-aprendizagem perante o uso da internet continua sendo o professor. Moran enfatiza seu papel dizendo:

(...) precisamos de mediadores, de pessoas que saibam escolher o que é mais importante para cada um de nós em todas as áreas da nossa vida, que garimpem o essencial, que nos orientem sobre as suas conseqüências, que traduzam os dados técnicos em linguagem acessível e contextualizada. (Moran, 1997, p. 151)

Portanto, para Dewey (1978) e Cysneiros (1996), o professor é o elemento essencial neste processo de mediação do aprendizado do aluno, sendo sua função ensinar ao aluno novas formas de leitura, possibilitando-lhe ler nas entrelinhas sem se impressionar com a aparência e a forma, permitindo-lhe também confirmar ou questionar as fontes e a veracidade ou a qualidade de citações e, acima de tudo, da informação. Dessa forma, tanto o papel do professor como o do aluno mudarão. Aquele passará a ser o intermediador, ajudando o aluno a analisar as fontes de informação que possuem as melhores evidências 
sobre um determinado fato ou assunto, centrando sua atenção não mais na função de transmissão de informações, mas sim na de mediação do saber. Já o aluno deverá deixar a posição de passividade, na qual apenas recebia informaçóes de livros e do professor, para se tornar um ser mais partícipe do seu processo educativo.

Então, professor e aluno terão de aprender a lidar com as novas tecnologias e também com os modelos tradicionais para adquirir as informações necessárias para sua formação profissional e pessoal. Como se percebe, o desafio não é simples, requer que professores e alunos se preparem para trabalhar com um universo tecnológico no qual eles ainda estão se iniciando.

Vivemos uma época em que o ensino presencial e a difusão pela internet acabarão se complementando. No processo educativo, as pessoas devem desaprender certos métodos, embora mantenham intacto o seu cabedal de conhecimentos. Dessa forma, o desafio da educação será

(...) arquitetar novas mentalidades. Para tanto devemos buscar, dentro e fora da escola, a complementaridade em objetivos que muitos julgam antagônicos: indução do espírito empreendedor e trabalho em equipe (...) a educação é força capaz de mediar os conflitos existentes e atenuar seus efeitos. (Marcovitch, 2002, p. 7)

Moran (1997, 2001 e 2003) e Assmann (2000) destacaram o processo de metamorfose da aprendizagem na sociedade da informação. Para eles, novas estratégias de ensino-aprendizagem foram e estão sendo engendradas com o uso das novas tecnologias da informação e da comunicação no campo da educação. Com a internet, alunos e professores introduzem formas diferentes de lidar com a informação e com o conhecimento.

Segundo Moran, a internet começa a ser um meio privilegiado de comunicação entre professores e alunos de modo que exige postura dinâmica de ambas as partes. Ao professor cabe o papel de orientar, estimular e acompanhar as atividades e pesquisas realizadas pelos alunos. Aos discentes, cabe a função ativa no manuseio de informação digital para a construção de seu conhecimento pessoal. O objetivo é educar os estudantes para a autonomia, permitindo-lhes que criem seu próprio saber, de acordo com seu ritmo. 
Assim, ensinar ou aprender, na era da informação, exige mudanças nos paradigmas ${ }^{2}$ de ensino. $\mathrm{O}$ importante é utilizar as tecnologias de forma que nos ajudem a aprender, levando-nos a transformar informação em conhecimento e, mais ainda, em sabedoria, pois a interligação permite aperfeiçoar o pensamento reflexivo como instrumento de emancipação humana.

De forma semelhante, Assmann relata que, no tocante à aprendizagem e ao conhecimento, chegamos a uma transformação sem precedentes das ecologias cognitivas. A sociedade da informação, também considerada sociedade da aprendizagem, ${ }^{3}$ tem, nas novas tecnologias da informação e da comunicação, seus elementos essenciais para organizar o mundo. As novas tecnologias assumem um papel ativo e co-estruturante nas formas de aprender e de conhecer. Desse modo, "o processo de conhecimento se transforma intrinsecamente em uma versatilidade de iniciativas, escolhas, opçôes seletivas e constataçôes de caminhos equivocados ou propícios” (Assmann, 2000, p. 11).

Nessa perspectiva, o importante é que o aluno "aprenda a aprender" e a ter consciência de que tudo muda e que nada é seguro, pois o conhecimento/saber é uma aventura incerta que comporta em si mesma, permanentemente, o risco de ilusão e de erro. Neste sentido, "o conhecimento é a navegação em um oceano de incertezas, entre arquipélagos de certezas" (Morin, 2002, p. 86). O que se destaca nesta definição é a importância de os professores se prepararem para ajudar seus alunos a lidar não com as verdades e certezas absolutas, mas sim com as incertezas do saber e da vida. Este papel de mediador e instigador do conhecimento, que o educador passa a assumir na era da informação, não reduz nem minimiza sua responsabilidade com a formação do sujeito, muito pelo contrário, deve contribuir para uma formação humana e ético-social.

Logo, a escola não deve ser oficina isolada onde se prepara o indivíduo, mas o lugar onde, numa situação real da vida, indivíduo e sociedade constituam uma unidade orgânica. Fazer o resgate de princípios humanísticos é também tarefa que cabe à escola realizar na figura de seus docentes. Até porque isso nenhuma máquina ou recursos tecnopedagógicos, por si, podem proporcionar, a não ser o professor de "carne e osso" (Cysneiros, 1996). 
As aventuras do conhecimento na sociedade da informação

Conhecida por ter um repositório inesgotável, a web dispõe de milhões de megabytes de informação, inclusive aquelas informaçôes que se prestam apenas à reprodução dos padróes de embotamento político e de passividade intelectual. Os mecanismos de busca de informação na internet evoluíram de forma surpreendente. Sistema de busca como o Google tem elevado bastante o estado da arte das pesquisas bibliográficas.

Ao analisar as formas de como as informaçōes da internet são usadas, Silva et al. (2003) evidenciam que o leitor da web não lê da mesma forma que o leitor de livros e revistas de papel. Este é um tipo de leitor fugidio, que faz leitura de forma superficial e rápida das páginas que acessa. A sua preferência é por texto com parágrafos curtos e objetivos. O leitor-navegador tem o mundo ao alcance do clique do mouse. Basta o texto tornar-se monótono para que o leitor se dirija a outras paragens, provavelmente para nunca mais voltar.

Com isso, pode-se dizer que surge uma nova forma de aprender, que nasce a partir do manejo dos vários instrumentos mais diretamente circunscritos à dinâmica ou à pulsação do mundo virtual. Contudo, "essa nova forma de aprender envolve tipos específicos de percepção e de cogniçãao do sujeito, demandando, por isso mesmo, a superação de formas tradicionais de aprendizagem pela recuperação, reinserção e dinamização das dimensões interativa e lúdica do processo" (Silva et al., 2003, p. 50).

Com a internet os textos passaram a ser documentos dinâmicos, abertos, onipresentes que remetem para um "corpus" praticamente infinito. Fala-se em página como uma unidade de fluxos. Ao se referir ao texto eletrônico - hipertexto -, Monteiro caracteriza-o como sendo destituído de materialidade, porém instituído de uma forma que poderá alterar o conceito de acervo e, sobretudo, da relação com a leitura. $\mathrm{O}$ hipertexto é entendido como uma forma eminentemente eletrônica, tendo como característica principal a apresentação da informação de maneira não-linear, como se a organização seqüencial e linear do papel fosse desmantelada. Esse tipo de texto se diferencia do texto impresso, porque "no hipertexto a informação encontra-se, de fato, armazenada em uma rede de nós conectados por ligações, podendo ser nós que 
contêm gráficos, textos, sons e imagens, os chamados documentos hipermídia” (Monteiro, 2000, p. 29). Isso não é possível encontrar no texto impresso, considerado uma longa seqüência linear de palavras que é dividida em linhas e páginas. Para Fonseca (2000, p. 61), o hipertexto é "base da navegação como a nova forma de leitura e escrita, é regido pelo princípio da não-linearidade, podendo ser comparável a um grande mapa nunca passível de ser totalmente desdobrado, podendo ser explorado somente através de pedaços minúsculos”.

Com a era da hipertextualidade, Lévy (1996) e Carvalho e Kaniski (2000) vão dizer que o saber se tornou móvel, sendo entendido como um fluxo de acontecimentos, isto é, uma sucessão de eventos que se realiza fora do estoque, na mente de algum ser pensante e em determinado espaço social. É um caminho subjetivo e diferenciado para cada indivíduo.

$\mathrm{O}$ ato de conhecer é visto como "uma cerimônia com ritos próprios, uma passagem simbólica, mediada por uma condição de solidão fundamental tanto para o emissor quanto para o receptor da informação, uma cerimônia que acontece em mundos diferentes" (Barreto, 2002 p. 71). Assim, conhecer é um ato de interpretação individual, uma apropriação do objeto pelas estruturas mentais de cada sujeito. É uma reconstrução das estruturas mentais do indivíduo, realizada por meio de suas competências cognitivas, ou seja, é uma modificação em seu estoque mental de saber acumulado, resultante da interação com a informação.

Moysés, Geraldi e Collares (2002) falam da aventura do conhecer como sendo um ato que promove um reencontro do conhecimento com o sujeito, o qual, aprendendo a olhar, percebe que o desafio do conhecimento é assumir que tudo que sabe e conhece pode ser desmontado, remontado, substituído, estabilizado e até mesmo loucamente fixado por uns tempos. Pellanda (2000), citando Maturana, Varela e Lévy, mostrará que o conhecimento não pode ser transmitido como quem copia um disquete. É preciso que cada um refaça a experiência e que re-crie o mundo a partir de seus próprios olhares.

Depreende-se de tudo isso que indivíduos e grupos não se satisfazem mais com saberes estáveis, buscam um saber-fluxo caótico, de curso dificilmente previsível, no qual se deve agora aprender a navegar. 
A relação intensa com a aprendizagem, a transmissão e a produção de conhecimento não é mais reservada a uma elite, mas a toda a massa de pessoas em suas vidas cotidianas e em seus trabalhos.

Aprendizagem na sociedade da informação: uma leitura do processo de ensino-aprendizagem na perspectiva da bricolagem ${ }^{4}$ e da rizomática

"Bricolagem" é um termo oriundo do francês, proposto pela primeira vez por Lévi-Strauss $(1976)^{5}$ para se referir a trabalho manual feito de improviso, aproveitando toda a espécie de materiais e objetos disponíveis. De forma geral, bricolagem relaciona-se com os trabalhos manuais ou de artesanato doméstico, todavia, de modo específico, trata-se do aproveitamento de coisas usadas ou partidas cuja utilização se modifica e se adapta a outras funçóes.

Segundo Lévi-Strauss, o bricoleur ${ }^{6}$ trabalha com as mãos, usando meios indiretos se comparados com os do artista. O bricoleur está apto para executar grande número de tarefas diferentes. Ele subordina cada uma delas à obtenção de matérias-primas e de ferramentas, concedidas e procuradas na medida do seu projeto. Para Lévi-Strauss, o conjunto dos meios do bricoleur não se pode definir por um projeto; define-se somente por sua instrumentalidade, para dizer de maneira diferente e para empregar a própria linguagem do bricoleur: os elementos são recolhidos ou conservados, em virtude do princípio de que isto sempre pode servir. Segundo ele, cada elemento representa um conjunto de relaçóes, ao mesmo tempo concretas e virtuais. $\mathrm{O}$ bricoleur dirige-se a uma coleção de resíduos de obras humanas, isto é, a um subconjunto da cultura: "O bricoleur, posto em presença de dada tarefa, ele não pode fazer seja lá o que for; deverá também começar por inventariar um conjunto predeterminado de conhecimentos teóricos e práticos, de meios técnicos, que restringem as soluções possíveis" (Lévi-Strauss, 1976, p. 40).

Wenth (2003), ao se referir à bricolagem, evidencia que esta tem o sentido de um trabalhar com o inesperado, com aquilo que se tem à mão, um adaptar-se às circunstâncias; refere-se ao trabalho de amador. Trabalho em que a técnica é improvisada, adaptada ao material e às circunstâncias existentes. As criações da bricolagem reduzem-se sempre a um arranjo novo de elementos, já que novos universos nascem de 
seus fragmentos. Por sua vez, Taddei (2000), fazendo uma leitura de $O$ pensamento selvagem de Lévi-Strauss, dirá que bricolagem é a atividade por intermédio da qual o indivíduo, pela criação do instrumental disponível, por tentativa e linguagem por meio da utilização de referenciais textuais e culturais aparentemente desconexos, encontra novas soluções. Conforme também evidenciou Walty (2004), LéviStrauss usa a imagem da bricolagem para distinguir o pensamento mítico do pensamento científico. O primeiro apóia-se no signo, ao passo que o segundo se vale dos conceitos.

Contemporaneamente, a bricolagem pode ser usada para traduzir uma prática dita pós-modernista de transformação ou estilização de materiais preexistentes em novos trabalhos (não necessariamente originais). Na sociedade da informação, o termo passou a ser sinônimo de colagem de textos ou extratextos para a produção de uma nova obra ou atividade, já que o texto que se constrói a partir de uma dinâmica da bricolagem não admite a possibilidade de ser governado por qualquer lógica científica e caminha para uma conclusão inesperada.

Os diversos procedimentos adotados pelos alunos, que vão desde a pesquisa de fontes até a concretude do trabalho final, são um trabalho quase que de "garimpagem", para se encontrar a informação desejada, num mar quase infinito de possibilidades que é a internet. Com a atitude de um bricoleur, o aluno-navegador faz o trabalho de busca, de recortes e de colagens que tem como base os textos obtidos no espaço virtual e, a partir daí, começa um verdadeiro trabalho de "alfaiataria” que envolve cortes, recortes, ajustes, reajustes e colagens. Tudo é feito na tentativa de construir ou produzir seu próprio conhecimento.

As críticas são cada vez mais ácidas quanto a esta forma de construção, tachada de cópia e de plágio. Há uma crescente sinalização para os efeitos desastrosos que essa prática pode trazer para a formação intelectiva e profissional dos acadêmicos. Contudo, queremos promover outro tipo de reflexão - sem querer desmerecer esta problemática que traz como pronto nevrálgico a questão das novas formas de ensino e aprendizagem, possibilitadas graças à introdução das novas tecnologias da informação e comunicação no campo pedagógico. Logo, considerar-se-á que as novas estratégias produzem também verdadeiras idiossincrasias no sujeito que aprende. Por isso apostamos na invenção de formas diferentes de se proceder com o saber e com a informação. 
É verdade que análises feitas por Paldês (1999) e Cruz (2004 e 2005), sobre as formas de uso pedagógico da internet por alunos acadêmicos, demonstraram que é inimaginável pensar o processo de ensino-aprendizagem sem a utilização dos recursos da rede mundial de computadores. Todavia, foi observado nesses estudos que muitos recursos ainda são subutilizados, embora cada vez mais o espaço virtual seja utilizado de forma sistemática para buscar informaçôes quando da realização de atividades e de trabalhos acadêmicos.

Sabemos dos excessos no uso dos recursos da rede mundial de computadores, e das conseqüências negativas que a sua utilização indevida poderá trazer para a formação dos alunos, levando-os a uma formação acrítica e superficial. Todavia, um bom acompanhamento, por parte do professor, no sentido de orientar os discentes na forma de se proceder com a informação e os conteúdos usados, poderá tornar a internet um dos espaços pedagógicos mais produtivos destes novos tempos.

$\mathrm{Na}$ era da informação, a aprendizagem assumiu uma dimensão descentralizada e, cada vez menos, hierarquizada. Na perspectiva de Deleuze, apresentada por Gallo, a aprendizagem se coloca para além de qualquer controle. Assim, a aprendizagem na sociedade da informação deverá ser traduzida como

(...) algo que escapa, que foge ao controle, resistir é sempre possível. Desterritorializar os princípios, as normas da educação maior, ${ }^{7}$ gerando possibilidades de aprendizado insuspeitadas naquele contexto. $\mathrm{Ou}$, de dentro da máquina opor resistência, quebrar os mecanismos como ludistas pós-modernos, botando fogo na máquina de controle, criando novas possibilidades. (Gallo, 2003, p. 81)

No contexto da internet não interessa criar modelos, propor caminhos, impor soluçóes. Não se trata de buscar a complexidade de uma suposta unidade perdida. Não se trata de buscar integração dos saberes. Importa fazer rizoma ${ }^{8}$ viabilizar conexões; abalizar e viabilizar rizomas entre os alunos, fazer rizomas com projetos de outros professores e manter os projetos abertos.

Deleuze e Guattari (2004) criaram o conceito de rizoma para se referir à teoria das multiplicidades. O rizoma funciona como o ponto de partida para se pensar as multiplicidades por elas mesmas, visto que 
o fundamento do rizoma é a própria multiplicidade. Assim, numa perspectiva rizomática, qualquer ponto pode ser conectado a outro. O rizoma não fixa pontos nem ordens: há apenas linhas e trajetos de diversas semióticas, estados e coisas, e nada remete necessariamente a outra coisa. Um rizoma não começa nem conclui, ele se encontra sempre no meio, entre as coisas, "inter-ser". Ainda segundo os autores, um rizoma pode ser rompido e quebrado em algum lugar qualquer, mas também retoma segundo uma de suas linhas ou segundo outras linhas. Neste sentido, "todo rizoma compreende linhas de segmentariedade segundo as quais ele é estratificado, territorializado, organizado, significado, atribuído, etc.; mas também compreende linhas de desterritorialização pelas quais ele foge sem parar" (Deleuze \& Guatarri, 2004, p. 18). Ele é feito de direçóes móveis, sem início nem fim, mas apenas um meio, por onde ele cresce e transborda, sem remeter a uma unidade ou dela derivar. $O$ rizoma não é um sistema hierárquico, é uma rede maquínica de autômatos finitos a-centrados, não-significante e heterogêneo.

A aprendizagem rizomática seria, então, definida pela operação de subtração dos pontos de unificação do pensamento e do real, realizando um mapeamento e uma experimentação no real que contribuem para o desbloqueio do movimento e para uma abertura máxima das multiplicidades sobre um plano de consistência.

Com esse entendimento, na sociedade da informação não há espaço para a possibilidade de atos solitários, isolados; toda ação implicará muitos indivíduos. Toda singularização será, ao mesmo tempo, singularização coletiva. Logo, todo ato singular se coletiviza, e todo ato coletivo se singulariza.

O sistema rizomático, o qual se tornou a internet, rompe a hierarquização tanto no aspecto do poder e da importância quanto no aspecto das prioridades na circulação. Diz Gallo (2003, p. 95): "No rizoma são múltiplas as linhas de fuga e, portanto, múltiplas as possibilidades de conexóes, aproximações, cortes, percepçóes”.

Nessa perspectiva, a educação possibilita a cada aluno um acesso diferenciado às áreas do saber de seu interesse particular, possibilitando a realização de um processo educacional muito mais condizente com as exigências da contemporaneidade. O processo educativo é uma produção singular a partir de múltiplos referenciais. Nessa produção 
não se poderiam vislumbrar, de antemão, resultados. Uma educação rizomática abre-se para a multiplicidade, para uma realidade fragmentada e múltipla, sem a necessidade mítica de recuperar uma ligação, uma unidade perdida. Os campos de saber são tomados como horizontes, mas sem fronteiras, permitindo trânsitos inusitados e insuspeitos. Dessa forma,

(...) o processo educativo seria necessariamente singular, voltado para a formação de uma subjetividade autônoma, completamente distinta daquela resultante do processo de subjetivação de massa que hoje vemos como resultante das diferentes pedagogias em exercício. (Gallo, 2003, p. 98)

Com base nesses fundamentos, ensinar seria lançar sementes que não sabemos se germinarão ou não, ao passo que aprender seria incorporar a semente, fazê-la germinar, crescer e frutificar, produzindo o novo. Assim, a aprendizagem é entendida como "um processo sobre o qual não se pode exercer absoluto controle. Podemos planejar, podemos executar tudo de acordo com o planejado, tomando à luz um resultado insuspeitado, inimaginável” (op. cit., p. 103).

Há método para ensinar, porém não há método para se aprender, pois o aprendizado não pode ser circunscrito nos limites de uma aula, da audição de uma conferência, da leitura de um livro. O aprendizado ultrapassa todas essas fronteiras, rasga os mapas e pode instaurar múltiplas possibilidades.

Para Gallo, Deleuze compreende a criação intelectual como sendo um ato de autoplágio, ou seja, a criação de conceitos é, também, um ato de roubar ${ }^{9}$ conceitos de outros. O roubo é criativo, pois sempre transformamos aquilo de que nos apropriamos. Ele é capaz de motivar novas criações. Roubar é contrário a plagiar, a copiar e a imitar. É recorrer ao que já existe, pois ninguém produz do nada, do vazio. A produção depende de encontros, encontros são roubos e roubos são sempre criativos. Roubar um conceito é produzir um conceito novo, porque cada conceito remete a outros conceitos, não somente em sua história, mas em seu devir, em suas conexôes presentes. Cada conceito tem componentes que podem ser, por sua vez, tomados como conceitos. Os conceitos vão, pois, ao infinito e, sendo criados, não são jamais criados do nada. 
De forma parecida, Kastrup explorou o conceito de aprendizagem de Deleuze. Para ela, a aprendizagem é vista como um movimento de vaivém, como uma série de saltos do objetivo para o subjetivo e vice-versa, unida à possibilidade de chegar, nesse momento, à essência do signo ou sua diferença. Desse modo, o aprendiz da sociedade da informação

(...) não é aquele que aborda o mundo por meio de hábitos cristalizados, mas o que consegue permanecer sempre em processo de aprendizagem. $\mathrm{O}$ processo de aprendizagem permanente pode, então, igualmente, ser dito de desaprendizagem permanente. Em sentido último, aprender é experimentar incessantemente, é fugir ao controle da representação. É também, nesse mesmo sentido, impedir que a aprendizagem forme hábitos cristalizados. (Kastrup, 1999, p. 151)

Aprender é estar atento às variações contínuas e às rápidas ressonâncias, mas isso implica, ao mesmo tempo, certa desatenção aos esquemas práticos de recognição. Aprender é, antes de tudo, ser capaz de problematizar, ser sensível a variaçôes materiais que têm lugar em nossa cognição presente. A aprendizagem tem como base seu caráter inventivo. Desse modo, aprender é aprender a aprender, para continuar aprendendo e inventando a si mesmo e ao mundo. Aprender é, então, fazer a cognição se diferenciar permanentemente de si mesma, fazêla bifurcar-se. A invenção ${ }^{10}$ é, assim, uma política de abertura da cognição às experiências não re-cognitivas e ao devir.

Trata-se de uma política que mantém a aprendizagem sempre em curso por meio de agenciamentos, acoplamentos diretos, imediatos com aquilo que faz a diferença. A aprendizagem não cessa com o saber, não faz obstáculo à continuidade do processo de diferenciação de si mesmo. Aprender a aprender é também e, paradoxalmente, aprender a desaprender. Trata-se de aprender a viver num mundo que não fornece um fechamento preestabelecido, num mundo que inventamos ao viver, lidando com a diferença que nos atinge.

\section{Considerações finais}

Aprender na era da informação passou a depender, em grande parte, da capacidade ativa e dinâmica de professores e alunos. Assim, o que temos que aprender na e da vida não é propriamente a resolver 
problemas, mas administrá-los com inteligência. Dessa forma, "aprender não pode aludir, nunca, a uma tarefa completa, a um procedimento acabado ou a uma pretensão totalmente realizada; ao contrário, indica vivamente, à dinâmica da realidade complexa, a finitude das soluções e a incompletude do conhecimento" (Demo, 2000a, p. 49). Por tudo isso o conceito de aprendizagem precisa ser ampliado, numa direção que articule objetividade e subjetividade, respeitando não só os conhecimentos prévios dos alunos como também outros aspectos ou processos psicológicos que agem como mediadores entre o ensino e os resultados da aprendizagem.

Podemos dizer que, na sociedade da informação, aprende melhor quem descobre mais e mais profundos padrôes. A aprendizagem está, principalmente, na habilidade de estabelecer conexões, revê-las e refazêlas. Com isso, a aprendizagem deixa de ser algo passivo para tornar-se uma obra de reconstrução permanente, dinâmica entre sujeitos que se influenciam mutuamente. É fundamental saber ler a realidade com acuidade, para nela saber intervir com autonomia. Em síntese, compreende-se que a aprendizagem na era das novas tecnologias da informação exige uma política de produção de si e do mundo.

Tudo isso mostra que a construção do saber na era da internet é uma prática de bricolagem em meio a um contexto rizomático, já que o processo de aprendizagem acontece graças à construção de link que se pode realizar entre as diversas fontes de informação e de saber, o que, naturalmente, viabiliza novos modos de construção de saber e de aprender. Portanto, pode-se destacar que a não-hierarquização, a descentralidade e a desterritorialidade do saber e da informação são características marcantes no processo de ensino-aprendizagem da sociedade da informação.

\section{Recebido em novembro de 2007 e aprovado em dezembro de 2007.}

\section{Notas}

1. De acordo com Carvalho e Kaniski (2000), o conceito de sociedade da informação foi formulado pela primeira vez em 1962 por Fritz Machlup.

2. Kuhn (1994) fala-nos que os paradigmas se estabelecem de forma normal e por revolução. Para ele, a condição para o surgimento de um novo paradigma está na incapacidade de o paradigma vigente não conseguir compreender os fenômenos na sua completude. 
Penso estarmos vivendo este momento, no campo da educação, já que a introdução das novas tecnologias da comunicação e da informação passou a exigir uma nova leitura sobre o processo de ensino-aprendizagem que o paradigma atual não está sendo capaz de realizar.

3. Assim como Gasque e Tescarolo (2004), Assmann prefere falar de uma sociedade da aprendizagem em vez de uma sociedade da informação ou do conhecimento.

4. Neste trabalho se optou por aportuguesar a palavra bricolage para "bricolagem".

5. Lévi-Strauss usa esta palavra para fazer uma análise entre o pensamento mítico e o pensamento científico. Seu objetivo é descrever a lógica de pensamento das civilizaçôes primitivas.

6. Bricoleur refere-se ao sujeito que faz, aquele que constrói ou cria a partir da perspectiva da bricolagem.

7. Segundo Gallo, Deuleze fala de uma educação maior para se referir àquilo que é produzido na macropolítica, nos gabinetes, expressa nos documentos. Mas considera uma outra educação denominada de menor, que está no âmbito da micropolítica, na sala de aula, expressa nas ações cotidianas de cada um. A educação menor é rizomática, segmentada, fragmentada e não está preocupada com a instauração de nenhuma falsa autoridade.

8. O conceito de rizoma, utilizando uma expressão dos próprios Deleuze e Guattari (2004), é um "roubo" que ele traz da botânica. Na botânica, rizoma é um tipo de caule radiciforme de alguns vegetais, formados por uma miríade de pequenas raízes emaranhadas em meio a pequenos bulbos armazenatícios. $\mathrm{Na}$ educação, refere-se à relação intrínseca entre as várias áreas do saber que se entrelaçam, formando um conjunto complexo, no qual os elementos remetem, necessariamente, uns aos outros e mesmo para fora do próprio conjunto. O rizoma não se presta nem à hierarquização nem a ser tomado como paradigma.

9. O roubo, aqui apresentado, não deve ser compreendido de forma negativa, como sendo uma apropriação indevida de outrem, mas, pelo contrário, demonstra a possibilidade de construção do novo a partir do já existente, coisa muito comum e necessária no campo da educação.

10. Para Kastrup, a invenção consiste num movimento de problematização das formas cognitivas constituídas. Do latim invenire, que significa encontrar relíquias ou restos arqueológicos, a invenção implica uma duração, um trabalho com restos, uma preparação que ocorre no avesso do plano das formas visíveis.

\section{Referências}

ASSMANN, H. A metamorfose do aprender na sociedade da informação. Ciência da Informação, Brasília, DF, v. 29, n. 2, p. 7-15, 2000.

BARRETO, A.A. A condição da informação. São Paulo em Perspectiva, São Paulo, v. 16, n. 3, p. 67-74, 2002.

BORGES, M.A.G. A compreensão da sociedade da informação. Ciência da Informação, Brasília, DF, v. 29, n. 3, p. 25-32, 2000.

Educ. Soc., Campinas, vol. 29, n. 105, p. 1023-1042, set./dez. 2008

Disponível em <http://www.cedes.unicamp.br> 
CARVALHO, I.C.L.; KANISKI, A.L. A sociedade do conhecimento e o acesso à informação: para que e para quem? Ciência da Informação, Brasília, DF, v. 29, n. 3, p. 33-39, 2000.

CRUZ, J.M.O. A internet no ensino superior: um estudo exploratório com alunos e professores da graduação. In: CONGRESSO DE INICIAÇÃO CIENTÍFICA DA UNIVERSIDADE FEDERAL DE SERGIPE, 5., 2004, São Cristóvão. Anais... São Cristóvão: PIBIC-CNPq; UFSE, 2004. v. 5. p. 441.

CRUZ, J.M.O. O uso da internet no ensino superior: um estudo exploratório com alunos de graduação. In: SEMANA DE EDUCAÇÂO, 5., ENCONTRO REGIONAL DE EDUCAÇÃO, 2., 2005, São Cristóvão. Anais... São Cristovão: UFSE, 2005. (CD-ROM).

CYSNEIROS, P.G. Professores e máquinas: uma concepção de informática na educação. In: CONGRESSO DA RIBIE - REDE IBEROAMERICANA DE INFORMÁTICA EDUCATIVA, 3., 1996, Barraquilha.

DEMO, P. O que aprender, afinal?. In: Demo, P. Conhecer e aprender: sabedoria dos limites e desafios. Porto Alegre: Artes Médicas, 2000a.

DEMO, P. Ambivalências da sociedade da informação. Ciência da Informação, Brasília, DF, v. 29, n. 2, p. 37-42, 2000 b.

DELEUZE, G.; GUATTARI, F. Mil platôs: capitalismo e esquizofrenia. 5. ed. São Paulo: 34, 2004. v. 1.

DEWEY, J. Vida e educação. 10. ed. São Paulo: Melhoramentos; Fundação Nacional de Material Escolar, 1978.

DOWBOR, L. A educação frente às novas tecnologias do conhecimento. Artigos on-line, 2000.

FALZETTA, R. Na era das tecnoaulas. Nova Escola, São Paulo, v. 15, n. 138, p. 55-61, 2000.

FONSECA, T.M.G. Subjetivação na perspectiva da diferença: heterogênese e devir. In: Pellanda, N.M.C.; Pellanda, E.C. (Org.). Ciberespaço: um hipertexto com Pierre Lévy. Porto Alegre: Artes e Ofícios, 2000 . 
GALLO, S. Deleuze e a educação. Belo Horizonte: Autêntica, 2003.

GASQUE, K.G.D.; TESCAROLO, R. Sociedade da aprendizagem: informação, reflexão e ética. Ciência da Informação, Brasília, DF, v. 33, n. 3, p. 35-40, 2004.

JORGE, M.T.S. Será o ensino escolar supérfluo no mundo das novas tecnologias? Educação \& Sociedade, Campinas, v. 19, n. 65, p. 163-178, 1998.

KASTRUP, V. A invenção de si e do mundo: uma introdução do tempo e do coletivo no estudo da cognição. Campinas: Papirus, 1999.

KASTRUP, V. Novas tecnologias cognitivas: o obstáculo e a invenção. In: Pellanda, N.M.C.; Pellanda, E.C. (Org.). Ciberespaço: um hipertexto com Pierre Lévy. Porto Alegre: Artes e Ofícios, 2000.

KUHN, T. A estrutura das revoluções científicas. São Paulo: Perspectiva, 1994.

LÉVI-STRAUSS, C. A ciência do concreto. In: Lévi-Strauss, C. $O$ pensamento selvagem. 2. ed. São Paulo: Nacional, 1976.

LÉVY, P. O que é o virtual. São Paulo: 34, 1996.

LÉVY, P. Cibercultura. São Paulo: 34, 1999.

MARASCHIN, C. Conhecimento, escola e contemporaneidade. In: Pellanda, N.M.C.; Pellanda, E.C. (Org.). Ciberespaço: um hipertexto com Pierre Lévy. Porto Alegre: Artes e Ofícios, 2000.

MARCOVITCH, J. A informação e o conhecimento. São Paulo em Perspectiva, São Paulo, v. 16, n. 4, p. 3-8, 2002.

MORAN, J.M. Como utilizar a internet na educação. Ciência da Informação, Brasília, DF, v. 26, n. 2, p. 146-153, 1997.

MORAN, J.M. Novos desafios na educação: a internet na educação presencial e virtual. 2001. Disponível em: <http://www.eca.usp.br./ prof/moran/uber.htm>. Acesso em: 12 out. 2005.

MORAN, J.M. Mudar a forma de ensinar e de aprender com as tecnologias: transformar as aulas em pesquisas e comunicação presencial-virtual. 
2003. Disponível em: <http://www.eca.usp.br./prof/moran/uber.htm>. Acesso em: 12 out. 2005.

MORIN, E. Os sete saberes necessários à educação do futuro. 6. ed. São Paulo: Cortez; Brasília, DF: UNESCO, 2002.

MONTEIRO, S.D. A forma eletrônica do hipertexto. Ciência da Informação, Brasília, DF, v. 29, n. 1, p. 25-39, 2000.

MOYSÉS, M.A.A.; GERALDI, J.M.; COLLARES, C.A.L. As aventuras do conhecer: da transmissão à interlocução. Educação \& Sociedade, Campinas, v. 23, n. 78, p. 91-116, 2002.

PALDÊS, R.Á. O uso da internet na educação superior de graduação: estudo de caso de uma universidade pública brasileira. 1999. Dissertação (Mestrado em Educação) - Universidade Católica de Brasília, Brasília, DF.

PELLANDA, N.M.C. Pierre Lévy e Humberto Maturana: convergências paradigmáticas. In: Pellanda, N.M.C.; Pellanda, E.C. (Org.). Ciberespaço: um hipertexto com Pierre Lévy. Porto Alegre: Artes e Ofícios, 2000.

SILVA, E.T. et al. A leitura nos oceanos da internet. São Paulo: Cortez, 2003.

TADDEI, R.R. Conhecimento, discurso e educação: contribuição para a análise da educação sem a metafísica do racionalismo. 2000. Dissertação (Mestrado em Educação) - Faculdade de Educação, Universidade de São Paulo, São Paulo.

VIERA, L.S. Uso da informática na criação de ambientes integrados de aprendizagem. In: CONGRESSO DA RIBIE - REDE IBEROAMERICANA DE INFORMÁTICA EDUCATIVA, 4., 1998, Brasília, DF.

WALTY, I. De lixo e bricolagem. Alceu, Rio de Janeiro, v. 5, n. 9, p. 6276, jul./dez. 2004. Disponível em: <http://publique.rdc.puc-rio.br/ revistaalceu/media/alceu_n9_walty.pdf>. Acesso em: 12 out. 2005.

WENTH, R.C. Bricoleur: uma possível imagem para o trabalhar da análise. In: CONGRESSO LATINO-AMERICANO DE PSICOLOGIA JUNGUIANA, 3., 2003, Salvador, BA. Disponível em: <http:// www.symbolon.com.br/artigos/bricoleur.htm>. Acesso em: 12 out. 2005. 